\title{
Ultrastructural Study of two Parasites Infecting Domesticated Turkey Meleagris_Gallopavo Linnaeus, 1758 (Galliformes: Meleagridinae) Qena, Egypt.
}

\author{
Soheir A. Rabie and Khalaf N. A. Ammar \\ Zoology Dept., Faculty of Science; South Valley University, Qena, Egypt.
}

\begin{abstract}
This work provides a detailed systematic morphology by optic and Scanning electron microscopy of two parasites Raillietina echinobothriida Megnin, 1880 and Spirora meleagaris $n$. sp. infecting domesticated turkey. The present study includes some important characters that not recorded in previous description. SEM revealed that the tegument of the first cestode exhibits, filamentous, microtriches and sensory papillae densely covered the tegument of entire body, rostellum armed with two rows of hummer-shaped hooks and provide by $16-20$ rows of small, rose thorn-shaped accessory spines. In addition, the present studies have observed a number of taxonomic features in Spirora meleagaris $n$. sp. that differ from those mentioned in the same genus, mouth circular, bounded by a cuticular three circles plates, five pairs of cephalic papillae, an inner circle of two pairs situated on the wall of the buccal cavity, one pair of larges submedian amphids, and an outer circle of two pairs papillae. Buccal cavity supported by four chitinious cusped molar teeth anteriorly directed .Vulva near the end of the first third of the body, vulvular lips prominent. The male has unique rose like shaped pedunculated and unarranged numerous distributed sessile cervical papillae at the second third of the body that are distinguishable from other spirorid.
\end{abstract}

Keywords: Raillietina echinobothriida, spirorid parasites, Meleagris_gallopavo, aves, spirura, Egypt.

\section{Introduction}

The domesticated turkey Meleagris gallopavo Linnaeus, 1758 is a large poultry bird, one of the two species in the genus Meleagris, Turkey meat is ranks second in the poultry sector, and compares favorably with domestic chicken for meat and egg production. In despite of the increasing economic importance of this bird for the ready-to-eat low fat food industry since the last decade; using its meat and eggs as major sources of protein and employing its feathers extensively for decorative purposes. Lately, the increase in the incidence of zoonosis, diseases transmissible from domestic animals to human, has been registered. The causative agents can be transferred by direct contact with infected animals, their excreta, by parasites or indirectly through contaminated environment (soil, food and water). It is believed that there are more than 200 registered zoonosis Klimpek et al., (2007). Data on helminths of domesticated turkeys are relatively very few and thus, the action of the parasitism affecting these hosts is little known. In Brazil, investigations related to the pathology induced by helminths in turkeys are restricted to those of the pioneer paper by Barretto and Mies-Filho (1942) and more recently to the results reported by Brener et al., (2006) describing the pathogenic action of the trematode Paratanaisia bragai, the nematodes Cheilospirura hamulosa, Heterakis gallinarum and the protozoan Histomas meleagridis infecting this avian host. But in Egypt Hussien (1991) and El-Azazy (1979) found that poultry are infected with cestodes $R$. echinobothridia and the peak of infection was in summer.

Gastrointestinal helminthes are distributed worldwide, among the helminth parasites of poultry, nematodes and cestodes constitute the most important group. Helminthes are known to compete with the infected hosts, lowering their productivity and in severe cases causing death by blocking the gastrointestinal tract (G.I.T) especially when the worm burden is high Soulsby (1982). Bawe et al., (2005) observed of lesions associated with gastrointestinal parasites of fowls in Nigeria. Helminth parasites were incriminated as major causes of unsoundness and lowering performance of poultry in Egypt (Khater, 1993). Avian cestodiasis constitutes one of the most common endoparasitism causing serious troubles in chicken production. Chicken cestodiasis not only cause loss of body weight of the raised chickens but also may cause several problems in affected flocks such as enteritis, loss of blood, loss of production, nervous manifestations and death Shahin et al., (2011). Also, cestodes especially Davanea spp. penetrates deeply into an intestinal mucosa and produce marked enteritis which is frequently hemorrhagic in heavy infestation Soulsby (1982). The adult parasite is infects the small intestine of fowl, from where it obtains nutrition from the digested food of the host. The tapeworm is responsible for stunted growth of young chicken, emaciation of adult and decreased egg production of hen Samad et al., (1986). Recently, Brener et al.,(2006) studied the lesions caused by the gizzard nematode Cheilospirura hamulosa Diesing, 1851 in turkeys from Brazilian backyard flocks, confirming its high pathogenicity, since this nematode species infects other galliform birds, mainly chickens and Pheasants, 
Ultrastructural study of two parasites infecting domesticated turkey Meleagris_gallopavo Linnaeus,

provoking severe gross and microscopic lesions in these hosts. He et al., (1990) showed that helminth infections had a significant effect on weight loss. The state of nutrition and body condition was below average in the chickens investigated. Rahman et al., (2009) showed that helminth infections parasites of Scavenging Chickens in Malaysia had a significant effect on weight loss. The economic importance of domestic fowls within the poultry industry, as well as the fact that domestic fowls are kept by many private households to augment their income, necessitated a better understanding of factors, such as gastro-intestinal parasites, influencing the successful rearing of these birds. Consequently studies have been conducted to assess the extent to which domestic fowls can serve as alternative hosts for their respective helminths and possibly be adversely affected by them.

Davaineidae is the name of a family of tapeworms that includes helminth parasites of vertebrates. There are 14 genus recorded under this family, of which Raillietina is the best understood and most extensively studied Schmidt (1986). The species of the genus Raillietina are parasites of major clinical importance for poultry Kassai. (1999) and their records in Qena are therefore important from veterinary point of view. The structure of the cestode tegument is of particular which interest to parasitologists, as these worms lack mouth and digestive system and, therefore, all nutrients must pass through the body wall Read et al., (1963). Earlier investigations of tapeworm morphology revealed that the free surface of the tegument is covered with specialized microvilli, thus resembling the brush range of morphologies, border of mammalian enterocytes Read, (1955).These processes have been referred to as microtriches Rothman, (1963), microvilli Beguin, (1966) and tegumental projections Morseth, (1966). Cestodes tegument represented a high degree of morphological specialization for performing diverse functions, which include nutrient absorption, digestion, protection, excretion, anchoring and traction for locomotion (Rothman, 1963; Morseth, 1966; Jones, 1975; Lumsden, 1975; Thompson et al., 1980; Coil, 1991; Hayunga, 1991; Palm et al., 1998).

Nematodes of the order Spirurida Oerley, 1885, are the most parasites infecting vertebrates Alvareze et al., (1995) in a Spanish population of this species infecting submucosa and free in the lumen of the esophagus and stomach host. The taxonomy of this group of nematodes is very difficult mainly because the species very often have no host specificity, besides the great variability of characters used for specific differentiation and many species were described based either on the study of a few specimens or on female specimens only. Spirura Blanchard, 1849 include 36 species occurring in vertebrate's worldwide Smales, (2001). The aim of the present study is to provide detailed morphological and taxonomical studies of these species, based on light and electron microscopic examination.

\section{Materials And Methods}

In this study a total of 8 birds were dissected and examined; helminthes parasites of them $3(48.4 \%)$. The birds were bought from Qena province then dissected and the alimentary tract was separated, intestinal mucosal scrap as well as the contents was washed several times with physiological saline $(0.9 \%)$ and after sedimentation, the sediments were examined under dissecting microscope for parasites. The isolated parasites were washed in saline solution and fixed in $10 \%$ buffered formalin. Specimens were stained in Acetic-Carmine, dehydrated and mounted in Canada balsam. Drawings were made with the aid of a camera Lucida.For SEM studies, recovered species were washed in phosphate buffered saline and fixed overnight in $2.5 \%$ gluteraldehyde (PH 7.4) at $4 \mathrm{C}^{\circ}$. Specimens were washed three times in phosphate buffer and post fixed in $1 \%$ Osmium tetraoxide in $0.1 \% \mathrm{M}$ Phosphate buffer and dehydrated through a graded series of ethanol. Complete dehydration was performed in two changes of absolute ethyl alcohol. Specimens were then mounted on stubs with double adhesive tape, coated with gold. The samples were examined with a high resolution scanning electron microscope (Joel 1200 Ex II).

\section{Result}

The taxonomical features of cestodes are based on the works of Khalil (1994) while nematodes collected were identified according the keys of York and Mapleston, (1926).To confirm the morphologic identification.

I -Raillietina echinobothriida Megnin, 1880 Fuhrmann, 1924 plate $(1,2)$

Order: Cyclophyllidea

Family: Davaineidae Braun, 1900

Genus: Raillietina Fuhrmann, 1920

Adult $R$. echinobothrida is a characteristic tapeworm structure, composed of a series ribbon-like body segments, gradually enlarging from the anterior end towards the posterior. It is whitish in color, highly elongated, dorso-ventrally flattened. The fresh parasites measure $21-25 \mathrm{~cm}$, mean $(23 \mathrm{~cm})$. The body is wide, and the rostellum armed with two rows of hooks which are hammer - shaped of 130- $185 \mu \mathrm{m}$ in length, and armed with16 - 20 rows of small, rose thorn-shaped accessory spines11-15 $\mu \mathrm{m}$. The scolex is globular, small and it is provided with unarmed four suckers, they are strongly muscular and measures $0.32-0.46 \mathrm{~mm}$ long, by $0.37-0.53$ $\mathrm{mm}$. which are the organs of attachment to the host. The neck is long and broad measures 1.3-2.5mm in length. 
Ultrastructural study of two parasites infecting domesticated turkey Meleagris_gallopavo Linnaeus,

The immature segments are broader than long, mature segments are also broader than long plate 2(a, b, c) and measures $0.90-1.2 \mathrm{X} 1.25 \mathrm{~mm}$.the common genital pores are unilateral alternating and regularly located at the posterior third of the lateral wall of the segment. The ovary is median, post-equatorial.bilobed appear, it measures 0.36-0.41X0.29-0.42mm.ootype is situated between ovarian lobes a small seminal receptacle runs in the middle and gives a saccular vagina which turns laterally to open by the female genital pore at the genital atrium. Uterus is sac like situated at the middle.A large compact vitelline gland mass lies in the mid-line of segment. Numerous number of testes (29 -34) are situated in two lateral fields on both sides. They measure 72 80X71-86 $\mu \mathrm{m}$. Vas differences leads into a swollen internal seminal vesicle they enters the cirrus pouch forming cirrus. Gravid segments are longer than broader and measures 3.7-4.3X1.6-1.8 mm .uterus is breaking up into egg capsules.

At higher magnification, the suckers, margin of suckers, center, surrounding region of the scolex and the rostellum were covered by filamentous microtriches. Within the circlet of hooks on the rostellum, the slender and filamentous microtriches were densely packed together, with a tendency for some spikes to coalesce or show transverse connections in some areas similar microtriches were observed on the suckers. The microtriches were slender, filamentous not as long as in the rostellum, but more densely packed together forming characteristic tufts inside the sucker plate $2(\mathrm{~d}, \mathrm{f}, \mathrm{g}, \mathrm{h}) \mathrm{The}$ tegument was found to be entirely covered with filamentous microtriches and around genital pore hair like shape plate $2(\mathrm{~g} \& \mathrm{~h})$. In addition to filamentous type, few sharply-ending electron-dense points could be seen on the margins of the suckers, their cavities and rest of the scolex region. The basal region of the gravid proglottides was interrupted by genital pores surrounded by numerous small papillae, and they are lack of microtriches in this region suggest that they are specifically atrophied during the transformation of immature to mature and then to gravid stage.

\section{2- Spirora meleagaris n.sp. Plates (3-7).}

Nematoda Rudolphi, 1808

Spiruroidea Railliet \& Henry, 1915

Order: Spiruridea Diesing, 1861

Family: Spiruridae Oerley, 1885

Subfamily:Spirurinae Raillit, 1915

Genus: Spirura Blanchard, 1849

Medium sized nematodes, they are more or less filiform worms, anterior end abruptly attenuated with rounded apex, posterior end rounded, body thick transversely striated, annular furrows with longitudinal folds ridges running along the total body seen posterior to the excretory pore; the striations are wide and transverse and each possesses longitudinal ridges or folds, mouth elongated terminally, surrounded by the chitins prolongation of the thickened vestibule, $0.04 \mu$ in both sexes. Lips inconspicuous or absent, Chitins buccal cavity (Pseudo buccal capsule) or vestibule is present. The anterior end is differentiated into two circular pseudo labia, each pseudo labium bears a single amphid and a pairs of oval cephalic papillae plate 3(a, c), a pairs of sub cephalic papillae plate3 (a, c), plate 4(c) and plate5 (f)

The esophagus is usually long cylindrical and divided into two parts, a shorter anterior muscular portion and a longer glandular posterior portion. Intestine is usually simple and without diverticula.(Plate, $3 \mathrm{a}$ ). Females are larger than males and amphidelphic. vulvular lips prominent , The vulva has a well developed sphincter and is located at second third of the body the vagina has muscular walls, giving rise to the two uteri opposed, containing immature eggs. Anterior ovary almost extends beyond the junction of esophagus and intestine, posterior ovary almost reaches the anus, and eggs are smooth and non embryonate. Male Spicules dissimilar and unequal.

Female. (Plates 4, 5): Body, 12.8 - 21.3mm long, $0.24-0.34 \mathrm{~mm}$ wide. Transverse cuticular striae being $2.5 \mu$. They appear highly corrugated towards the posterior end giving the body a general rough appearance. muscular oesophagus $0.32-0.39 \mathrm{~mm}$ long, $0.088 \mathrm{~mm}$ wide; glandular oesophagus $1.82 \mathrm{~mm}$ long and $0.133 \mathrm{~mm}$ wide. Nerve ring $0.29-0.35 \mathrm{~mm}$ and excretory pore circular $0.47-0.52 \mathrm{~mm}$ from anterior end.Vulva $3.9-7.8 \mathrm{~mm}$ from anterior end; eggs $0.043 \mathrm{X} 0.032 \mathrm{~mm}$. The tail bounded in shape

Male. (Plates 3, 6, 7): Body 11- $13 \mathrm{~mm}$ long, 0.22-0.26mm wide; transverse striae $0.9-2 \mu$ apart. Pharynx 0.09 $-0.14 \mathrm{~mm}$ long, $0.019-0.023 \mathrm{~mm}$ wide; muscular oesophagus $0.32 \mathrm{~mm}$ long, $0.078 \mathrm{~mm}$ wide. Nerve ring $0.28 \mathrm{~mm}$ from anterior end. Well small gubernaculum $0.042 \mathrm{~mm}$ long and $0.062 \mathrm{~mm}$ wide.

The spicules are unequal and dissimilar.The longer spicule measure $1.4-1.6 \mathrm{X} 0.27-0.29 \mathrm{~mm}$. the ratio between the two spicules is $4: 1$.

Caudal alae are well developed, supported by four preanal pairs of pedunculate papillae, Tail curved ventrally and bluntly. In both sexes, high magnification revealed that the cuticle of the cervical region is inflated forming a large cervical inflation, which is also transversely. four large submedian cephalic papillae, four large of outer labial papillae and two lateral amphids lies on the borders of a circular- shaped on top of the cephalic plate, buccal cavity supported by four chitinious cusped molar teeth anteriorly directed and the cuticular surface 
Ultrastructural study of two parasites infecting domesticated turkey Meleagris_gallopavo Linnaeus,

of the worm is transversely annulated and each annulus is further divided into $10-15$ transverse striations; the excretory pore which is small and circular is surrounded by an elevated cuticular rim. The cuticular transverse striae occurring along the entire body are distinctly seen posterior to excretory pore, with longitudinal folds. The width of these striae being $1.5-2 \mu \mathrm{m}$. it is highly corrugated towards the posterior end giving the body a general rough appearance .female have a protruding vulva which is directed forwardly and has elevated lip. The male has unique rose like shaped peduculated and unarranged numerous distributed sessile cervical papillae at the second third of the body that are distinguishable from other spirorid.

\section{Discussion}

Cestodes Davaineidae recovered from the intestine of a captive emu which had died in the Copenhagen by Krabbe, 1869.later, Fuhrman (1909) described another davaineid species, from an emu in Berlin. The present material corresponds very well to the description given by Movsesyan, (2003). This species is a parasite of poultry with cosmopolitan distribution Movsesyan (2003). The species of the genus Raillietina are parasites of major clinical importance for poultry Kassai (1999).Morphological changes in the tegumental surface of the strobila involved erosion of folds in the posterior region accompanied by an increasing degree of disorder in the arrangement of microtriches (plate $2 \mathrm{~g} \& \mathrm{~h}$ ). The atrophy of the microtriches is of interest, because the gravid segments have to be voided out from the host body. The degeneration of microtriches enables the above and at the same time confirms its prime function as adhesion in the host environment. Ultrastructural study revealed that proglottids are entirely covered with microvilli hair-like 'microtriches'. These microtriches are the absorptive structures for feeding. According to Smyth and McManus (1989), the delicate microtriches, which serve as the surface amplifying structures, resemble functionally the intestinal mucosa of higher animals. These investigators referred to these amplified microtriches in the surface layer as brush-border.

Apart from the role of microtriches in absorption of nutrients by the parasites as suggested by Rosario (1962), Rothman (1963) and Smyth, 1969, they also have been thought to aid the worms in resisting the intestinal peristaltic currents and in maintaining parasite's position. The investigations of Blitz and Smyth (1973) in $R$. cesticillus suggested that the rostellar microtriches differ significantly from those on the proglottides, by being generally longer and thinner. The electron dense cap was greatly reduced or was absent. If, as Rothman (1963) and others have suggested, absorption is limited to the medullar base of the microtriches with the spike acting mainly for locomotion and attachment, this would favour an absorptive function for the rostellar microtriches of $R$ cesticillus.The thin microtriches found mostly in the sub-scolex region may probably represent sites of increased absorptive and secretory activity. The teguments in the scolex, immature and mature segments were lined by posteriorly directed filamentous microtriches, interspersed with few short blade-like microtriches However, the tegument covering the pre gravid and post gravid regions of the strobila revealed the apparent disintegration of the microtriches to only small rounded tips. Similar to the reports of Berger and Mettrick (1971) and Andersen (1975), the basal region of the gravid proglottides was interrupted by genital pores surrounded by numerous papillae, and the lack of microtriches in this region suggest that they are specifically atrophied during the transformation of immature to mature and then to gravid stage. The atrophy of the microtriches is of interest, because the gravid segments have to be voided out from the host body.

The degeneration of microtriches enables the above and at the same time confirms its prime functions adhesion in the host environment.

Nematodes collected from the intestine of the domesticated meleagris turkey are included in the family Spiruridae Oerley, 1885 and subfamily Spirurinae Raillit, 1915. Diagnostic criteria of some of the previously described species of the genus Spirura from Africa and other parts of the world have been compiled from the literature and are included here.The present description of Spirurida differs significantly from that given by Lewis and Ashour (1983), Jorge et al., (2012) in the following characteristics, namely, the number of cephalic papillae, the presence of cervical papillae, the absence of pharyngeal teeth and in males the presence of four pre cloacal and absent of two post cloacal papillae- like structures, and the presence of longitudinal striae on the ventral surface of the caudal alae. In the present specimens there are pedunculated rose shaped papillae. Also, the range in measurements of body length and width is much reduced compared with the measurements given in the original description. Present species are closed resemble previously reported from the small intestine of buff backed heron Spirura talpa Mahdy and El-ghaysh, (1998) in measurement and caudal pedunculated papillae, of which there are almost always four pre anal pairs, Spicules were unequal and dissimilar.

The present Spirora meleagaris n. sp. has a number of distinguishing taxonomic and main characters which not observed from those mentioned in the same genus, mouth circular, bounded by a cuticular three circles of cephalic papillae, an inner circle of two pairs situated on the wall plate of the buccal cavity, one pairs of larges submedian amphids, and an outer circle of two pairs papillae. Buccal cavity supported by four chitinious cusped molar teeth anteriorly directed.Vulva near the end of the first third of the body, vulvular lips prominent. The male has unique rose like shaped peduculated and unarranged numerous distributed sessile cervical papillae at the second third of the body male that are distinguishable from other spirorid. 
Ultrastructural study of two parasites infecting domesticated turkey Meleagris_gallopavo Linnaeus,

The new species shares some characteristics with other spiruridae parasite, but can be differentiated by a unique combination of characters, body thick transversely striated, The cuticle has rugae or folds that described as longitudinal folds and external raised incomplete annulations; branched and interrupted on the cuticle surface help parasites to creeping and migration in its host, mouth circular, bounded by a cuticular three circles of cephalic papillae, an inner circle of two pairs situated on the wall of the buccal cavity, one pairs of larges submedian amphids , and an outer circle of two pairs papillae. Buccal cavity supported by four chitinious cusped molar teeth anteriorly directed. Amphids have been assumed to be chemoreceptors because they open to the outside, vulva near the end of the first third of the body, vulvular lips prominent. The male has unique rose like shaped peduculated and unarranged numerous distributed sessile papillae at the third end of the body that are distinguishable from other spirorid. The chitinous 4 teeth are probably used during penetration into and migration through the intestinal wall of the host; while the different types of sensitive papillae and gabernaculum served for orientation during sexual mating. It can be claimed that our morphological findings had a close accordance with main characters recorded by Alvarez et al., (1995) for Spirura dentate.

In addition, the present studies have observed a number of taxonomic features in Spirora meleagaris n. sp that differ from those mentioned in the same genus, mouth circular, bounded by a cuticular three circles of cephalic papillae, an inner circle of two pairs situated on the wall of the buccal plate, one pairs of larges submedian amphids, and an outer circle of two pairs papillae. Buccal cavity supported by four chitinious cusped molar teeth anteriorly directed.The male has unique rose like shaped peduculated and unarranged numerous distributed cervical sessile papillae at the second third the body that are distinguishable from other spirorid.The scanning electron microscope studies have revealed a number of cephalic and caudal characters that differ from those described in Spirura dentata Monning (1938) by Alvareze et al.,(1995), the original drawing shows four simple denticles on the inner wall of the oral opening; a pairs of longitudinal ridges running along the total body and he also mentions a second pair of papillae in the second third of the tail of the mail; in the present specimens electron microscope reveals that this denticles are four molar cusped teeth and longitudinal folds with caudal papillae are present

Hence the present material have obvious characters of Spirura Blanchard,1849 and, for this reason, is placed under this genus as a new species because mouth have two circles of cephalic papillae, an inner circle of four larges papillae situated on the wall plate of the buccal cavity just inside the mouth and an outer circle of four larges submedian papillae and two lateral amphids., buccal cavity supported by four chitinious cusped molar teeth anteriorly directed, there are several types of cephalic, cervical and caudal sensory papillae are present and female vulva is near to the middle of the body.

\section{References}

[1]. Alvarez,M.F., G.Barreiro,J,A,Cordeiro,E.Paniagua and M.L.Sanmartin (1995): A scanning electron microscope of the nematode Spirura dentate (Spiruroidea) with notes on the morphometric variation in a Spanish population of this species. Folia parasitological 42:229-237.

[2]. Andersen KI. (1975): Comparison of surface topography of three species of diphylopothrium (Cestoda, Pseudophyllidea) by scanning electron microscopy. Int J Parasitol 5:293-300.

[3]. Barretto JF, Mies-Filho A. (1942): Primeiras observações sobre a presença de "Tamerlanea bragai" (Violantino Santos, 1934) nos rins de Meleagris gallopavo domestica, Ministério da Agricultura, Instituto de Biologia Animal, Rio de Janeiro, 3 pp.

[4]. Bawe N. M. , Ajanusi .o. J. ,Agbede R. I.and Esievo K. A. N.(2005): Observation of lesions associated with gastrointestinal parasites of guinea fowls (Numida meleagris galeata) in Zaria Nigeria. Isah - Warsaw, Poland Vol 2. 511.

[5]. Beguin F. (1966): Elude an microscopic electronique de la cuticle et de res structures as sociees chez quelques cestodes d'histologie comparee Z. Zellforsch MikrosAnat 72:30-46.

[6]. Berger J and Mettrick (1971): Microtrichial polymorphism among hymenolepid tapeworms as seen by scanning electron microscopy.TransAm Microsc Soc 90:393-403.

[7]. Brener B., Tortelly R., Muniz-Pereira LC. and Pinto RM (2006): First report of Cheilospirura hamulosa (Diesing, 1851) (Nematoda, Acuarioidea) in turkeys, Meleagris gallopavo (L., 1758) (Aves, Phasianidae) in Brazil: prevalence and pathology. Arq Bras Med Vet Zootec 58: 287-290.

[8]. Blitz NM. and Smyth JD. (1973): Tegumental ultrastructure ofRaillietina cesticillus during the larval-adult transformation, with emphasizes on the rostellum. Int. J. Parasitol 3:561-570.

[9]. Coil WH. (1991): Platyhelminthes: Cestodea. In: Harison, F.W. Bogtish, B.G. (Eds.) Microscopic anatomy of invertebrates. 3 : Wiley Liss, New York. pp 211-283.

[10]. El-Azazy O.M.(1979): Studies on the helminth parasites of poultery in Sharkia governorate. Thesis,M.V.Sc.Fact.Vet.Med.,Zagazig Univ.

[11]. Fuhrmann.O.(1909): Neue Davaineiden. Centralbl. Bokteriol.Parasitol.I.Abt 49.94-124.

[12]. Hayunga EG. (1991): Morphological adaptations of intestinalhelminths. J Parasitol 77:865-873.

[13]. He S, Susilowati V E H S, Purwati E and Tiuria R. (1990): An estimate of meat production loss in native chicken in Bogor and its surrounding districts due to gastrointestinal helminthiasis. Proceedings of the 5th National Congress of Parasitology, Pandaan, Pasuruan, East Java, 23-25 June 1990, 57.

[14]. Hussien M.F.I., (1991): some morphological studies on internal parasites of domestic pigeons in giza governorate. thesis,m.v.sc.fact.vet.med,cairo uni.

[15]. Jones A. (1975): The morphololgy of Bothriocephalus scorpii(Muller). (Pseudophyllidea, Bothriocephalidae) fromlitoral fishes in Britain. J Helminthol 49:251-261.

[16]. Jorge Luis Peralta-Rodrı'guez, Juan Manuel Caspeta-Mandujano, and Jose’ Antonio Guerrero (2012): A new spirurid (Nematoda) parasite from mormoopid bats in Mexico. J. Parasitol., 98(5), pp. 1006-1009. 
Ultrastructural study of two parasites infecting domesticated turkey Meleagris_gallopavo Linnaeus,

[17]. Kassai T. (1999): Veterinary helminthology. Oxford, Butterworth-Heinemann, 260 pp.

[18]. Khalil L. F, Jones A. and Bray R A. (1994): Keys to the cestode parasites of vertebrates. Wallingford, UK: CAB International, 751.

[19]. Khater, H.F.(1993) : Studies on enteric helminth parasitites in domestic birds . M.V.Sc. Thesis.Fac. Vet. Med. Banha, Zagazig University.

[20]. Klimpel S., M. Forster and S. Gunter, (2007): Parasite fauna of the bank vole (Clethrionomys glareolus) in an urban region of

[21]. Germany: reservoir of zoonotic metazoan parasites? Parasitol Res., 102: 69-75.

[22]. Lewis, J.W.and Ashour, A.A. (1983): The morphology of Dentostometia kuntri (Oxyuroidea :Nematoda) from Egyptian rodents. Journals of helminthology, 56:159-168.

[23]. Lumsden R.D. (1975): Parasitological review. Surfaceultrastructure and cytochemistry of parasitic helminths. Exptl Parasitol 37:267-339.

[24]. Mahdy O.A. and El-ghaysh A.(1998): Spiruroid parasites of Buff backed heron (Ardeola ibis ibis with a new species of Cordonema and Microtetrames together with a key to the genera of Acuaridae Seurat,1915.J.Egypt.Ger,Soc.Zool.,Vol.27(D),Invertebrate Zoology and Parasitology.73-89.

[25]. Megnin. (1881): Referred from The Fauna of British India including Ceylon and Burma. Cestoda,Vol.II by Southwell, T. 1930.Taylor and Francis, London. pp 97-99.

[26]. Moning H.O. (1938): Anew Spirurid nematode from a mongoose. In:livro Jubilar de Prof.L.Travassos.Rio de Janeiro,pp.333-336.

[27]. Morseth D.H. (1966): The fine structure of the tegument of adultEchinococcus granulosus, Taenia hydatiglna and Taeniapisiformis. J. Parasitol. 52:1074-1082.

[28]. Movsesyan S.O. (2003): Davaineates - tapeworms of animals and man. In: Beer, S.A. (Ed.) Essentials of Cestodology. Volume 13. Part 1.

[29]. Moscow, Nauka, 395pp. (In Russian).

[30]. Palm H.W, Polynton S.L and Rutledge P. (1998): Surface ultrastructure of plerocercoids of Bombycirhynchus sphyraenaicum (Pinter, 1930), (Cestoda: Trypanorhyncha). Parasitol Res 84:195-204

[31]. Rahman, A., Hasber S. and Mohd S. G. (2009): Helminthic Parasites of Scavenging Chickens (Gallus domesticus) from Villages in Penang Island, Malaysia. Tropical Life Sciences Research, 20(1), 1-6.

[32]. Read C.P. (1955): Intestinal physiology and the host-parasite relationship. In: Some physiological aspects and consequences of parasitism. (Ed). W. H. Cole. Rutgers University Press: New Jersey. pp 27-49.

[33]. Read C.P, Rothman A and Simmons JE. Jr. (1963): Studies on membrane transport, with special reference to parasite-host integration.AnnNYAcad Sci 113:154-205.

[34]. Rothman A.H. (1963): Electron microscope studies of tapeworms. The surface structure of Hymenolepis diminuta. Trans Am Microsc Soc 82:22-30.

[35]. Rosario B. (1962): The ultrastructure of cuticle in cestodes, Hymenolepis nana and Hymenolepis diminuta. In: S.S

[36]. Breese, Jr. (Ed), Electron microscopy, 5th Internatl. Cong. Electron Micros. Academic Press, NY. Pp11-12.

[37]. Samad M.A., Alam M.M. and Bari A.S. (1986): Effect of Raillietina echinobothrida infection on blood values and intestinal tissues of domestic fowls of Bangladesh". Veterinary Parasitology 21 (4): 279-284. PMID 3776079.

[38]. Schmidt, G.D. (1986): CRC hand book of tapeworm identification (CRC press,Ine., Boca Raton.Florida.USA).

[39]. Shahin, A.M.;1Lebdah, M.A.1; Abu-Elkheir,S. A.2 and Elmeligy, M.M.2, (2011): Prevalence of Chicken Cestodiasis in Egypt.New York Science Journal,;4(9).

[40]. Smales, L. R. (2001): Protospirura kaindiensis n. sp. (Spirura: Spiruridae) and other helminths from Pseudohydromys (Muridae: Hydromyinae) from Papua New Guinea. Journal of Parasitology 87: 169-172.

[41]. Smyth J.D. (1969): The physiology of cestodes. Oliver and BoydLtd., London. 1969. pp 279.

[42]. Smyth J.D. and Mc Manus D.P. (1989): The physiology andbiochemistry of cestodes. Ph. D. Thesis. CambridgeUniversity.

[43]. Soulsby, E.J.L (1982): Helminths, Arthropods, Protozoan of domesticated animals. London English Language book Society and Bailliere Tindall. Pp 3 - 84 .

[44]. Thompson RCA, Hayton AR. and Sue LPJ. (1980): An ultrastuructural study of the microtriches of adults Proteocephalus tidswelli (Cestoda: Proteocephalidae). Z.Parasitenk 64:95-111

[45]. York,W. and Maplestone,P.A. (1926) : The nematode parasites of vertebrates,London.
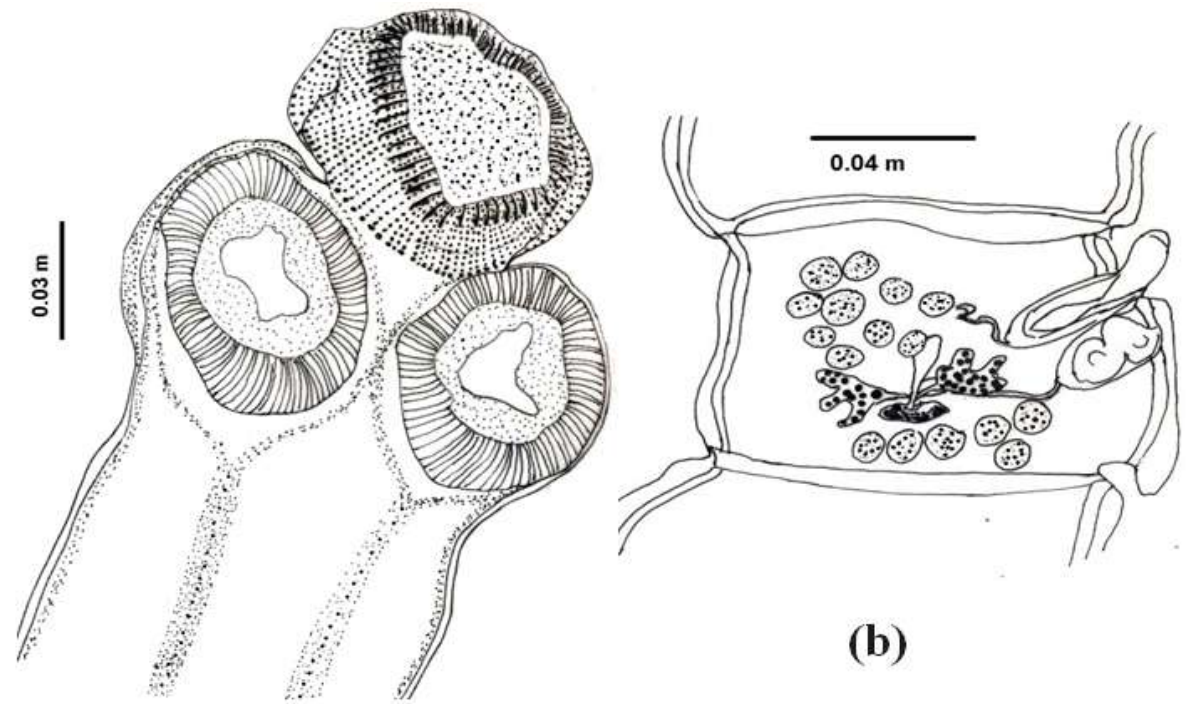

(a) 


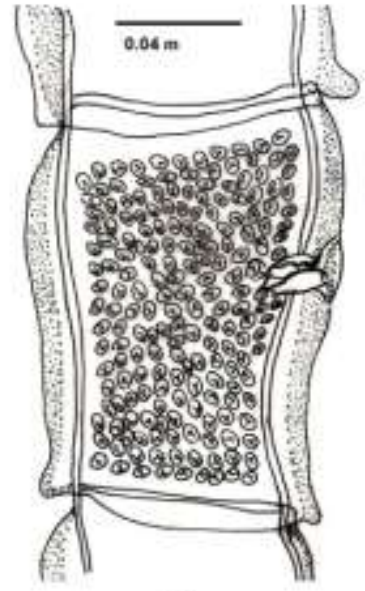

(c)

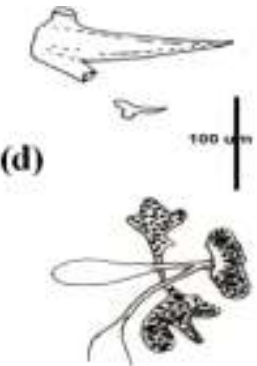

(e)

(f)

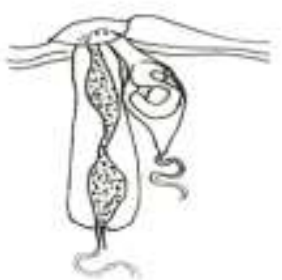

Plate : (1) :Camera lucida drawing R.echinobothriida .(a) scolex with long neck showing rostellum with 2 rows of hammer shaped hooks,(b)mature segment have numerous of testes(C)gravid proglottide (d) hooklets(e)a pair of lobed ovaries(f) genital opening and cirrus pouch.
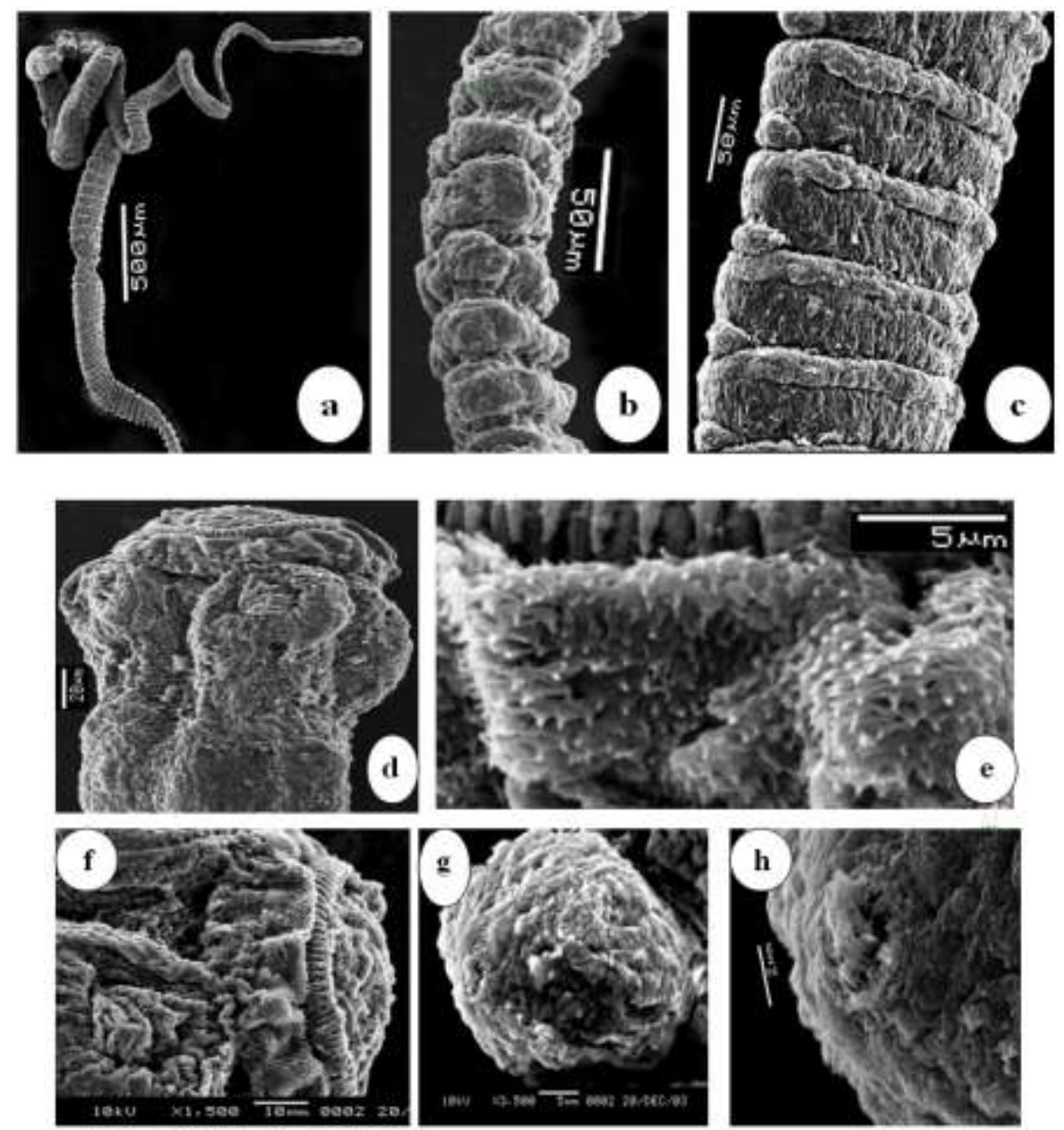

Plate (2 ): R.echinobothriida SEM micrographs showing ; (a) complete tapeworm, (b)immature segments,(c) mature segments showing cirrus in genital opening.,(d) scolex with long neck illustrating it bears four suckers and evaginated rostellum( e\&f) high magnification of rostellum showing crown hooks and rows of hooklets and tegumental surface of the sucker region showing uniform filamentous microtriches densely packed together tufts inside the sucker forming characteristic., (g\&h) high magnification of longer cirrus poush showing filamentous microtriches 


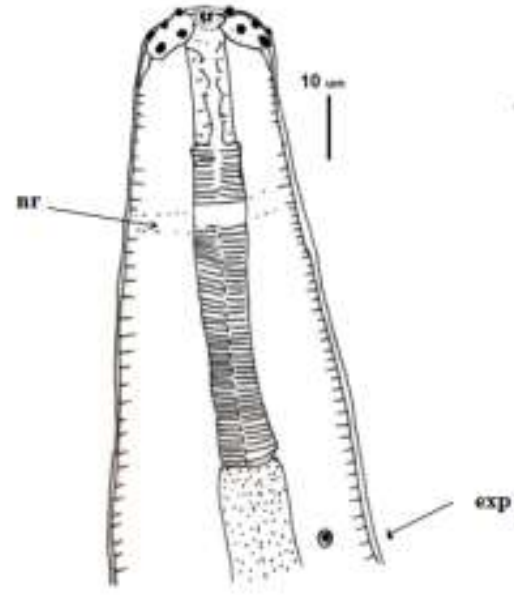

(a)

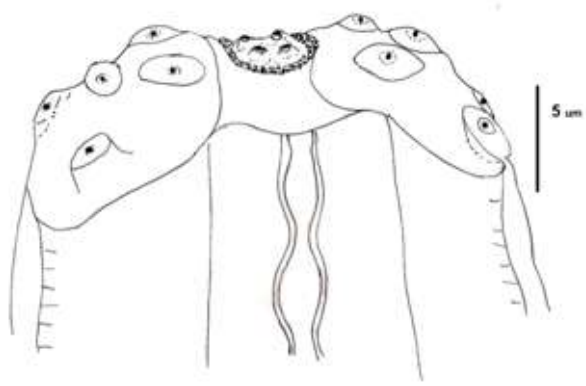

(c)

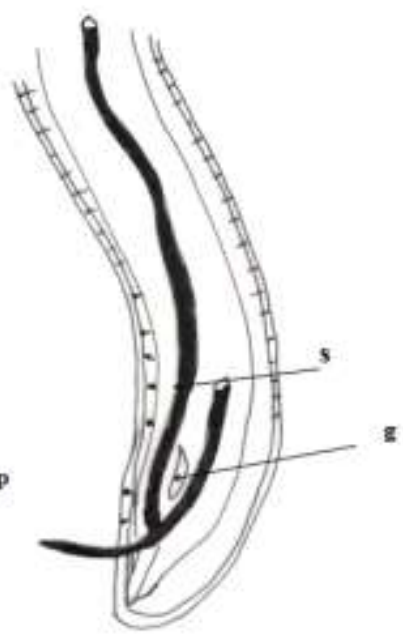

(b)

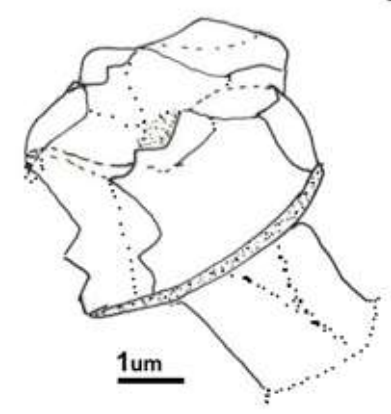

(d)

Plate (3) : Camera lucida drawing male Spirora meleagaris $n$. sp. of anterior and posterior ends showing arrangement of cephalic papillae and teeth, (a,c), , unequal spicules (b), pedunculated rose shape papilla $(\mathrm{d})$. $(\mathrm{g}=$ gubernaculums, $\mathrm{nr}=$ nerve ring, $\mathrm{s}=$ spicule and $\exp =$ excretory pore)

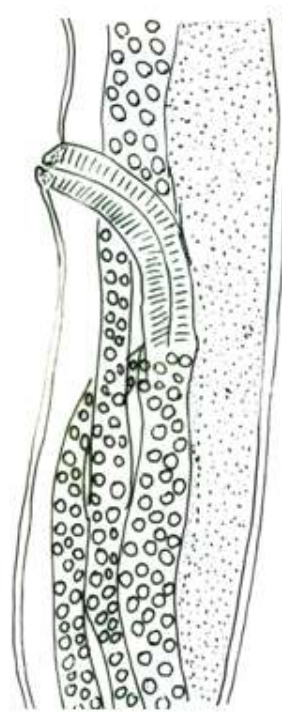

(a)

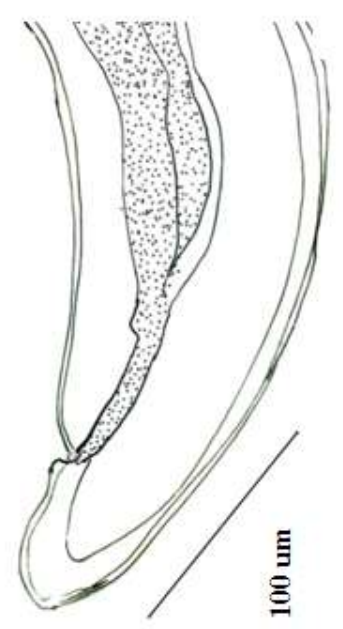

(b) 

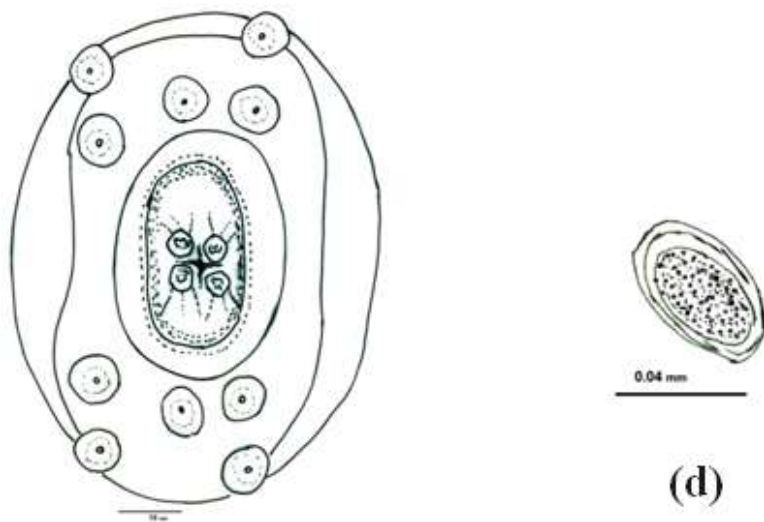

(c)

Plate (4): Camera Lucida drawing female of Spirora meleagaris n. sp.(a) Vulva region, (b) posterior end, (c) oral aperture of en faces apical view. (d) Egg.
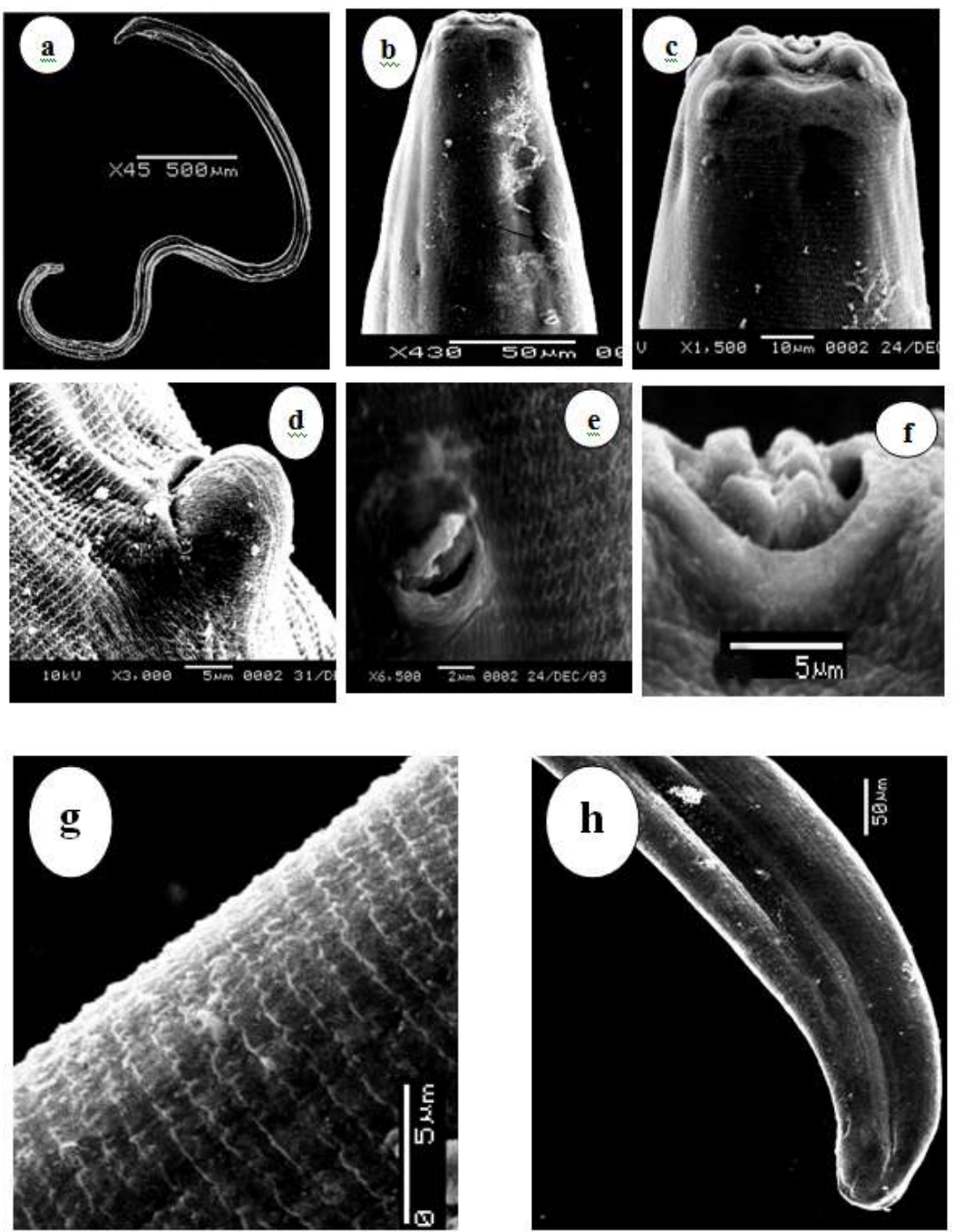

Plate (5): SEM micrographs Spirora meleagaris n. sp. female showing whole mount (a), anterior end with excretory pore(b), high magnification of mouth showing arrangement of cephalic papillae and 4 molar teeth (c),vulva (d).excretory pore (e), 4 molar cusps teeth(f), cuticle transverse striations (g). posterior end(h). 

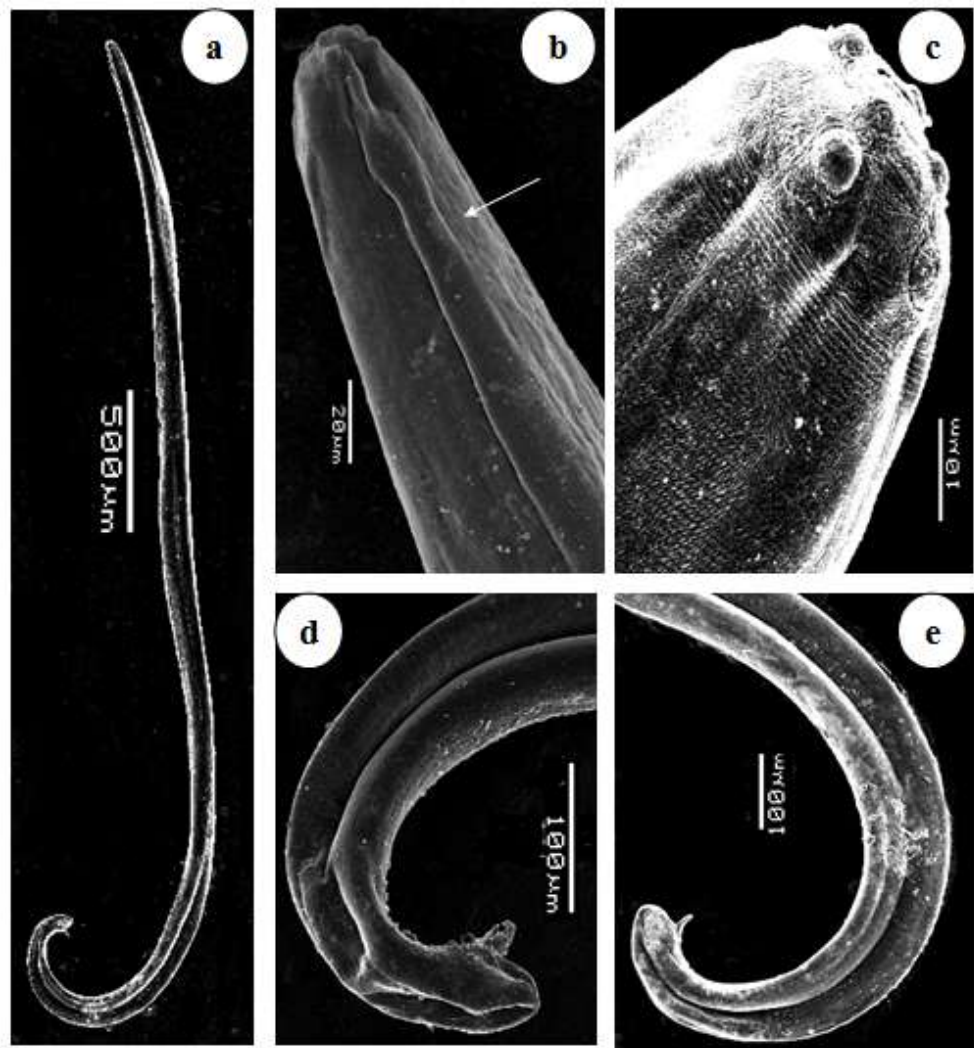

Plate (6): Spirora meleagaris n. sp. male SEM micrographs showing whole mount (a), anterior end showing beginning longitudinal folds and excretory pore(b), high magnification of the mouth note beginning of transverse striation (c), posterior end showing unequal spicules with caudal papillae, longitudinal folds and the tail blunt, with small caudal alae and slightly curved ventrally (d, e).
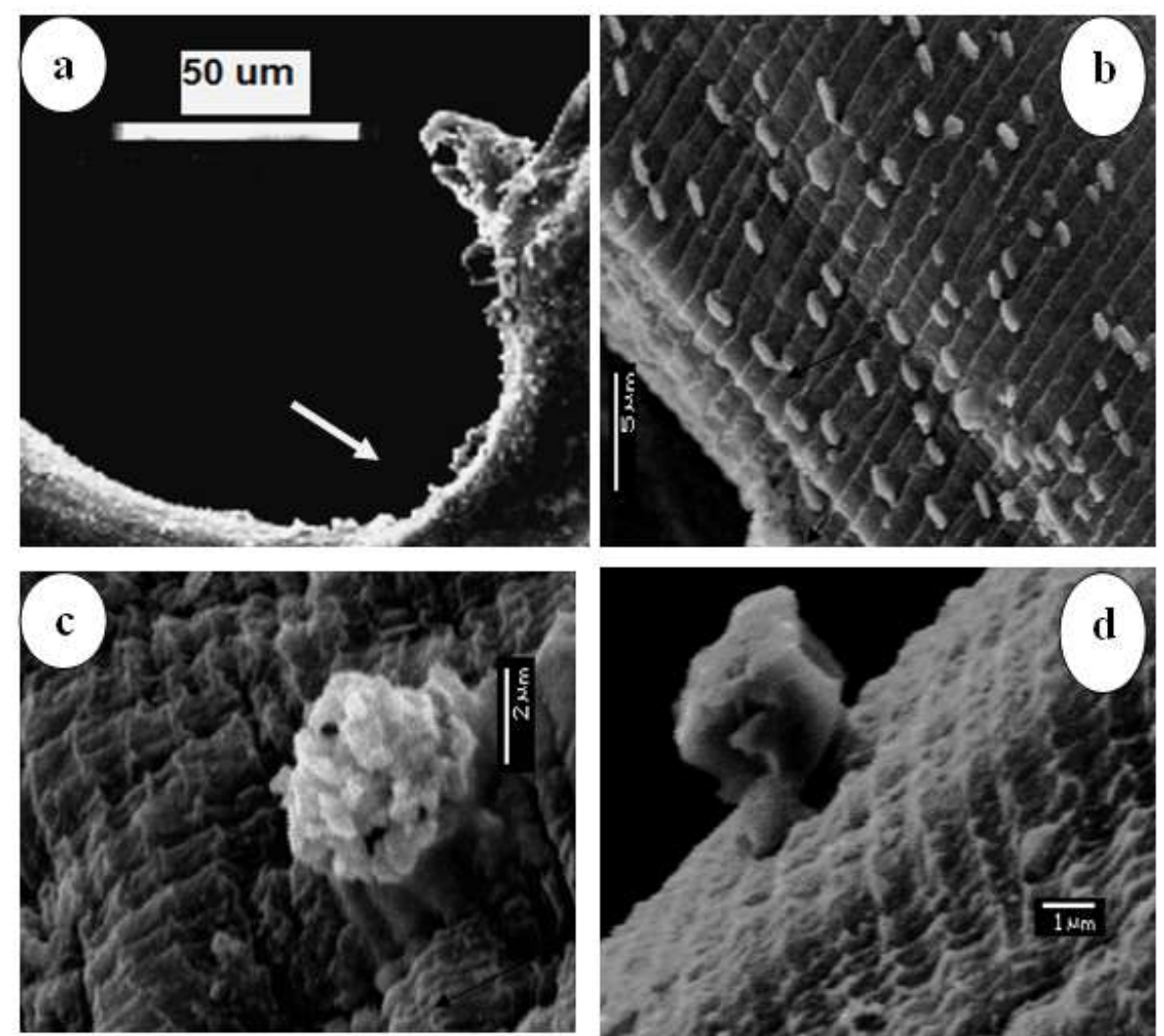

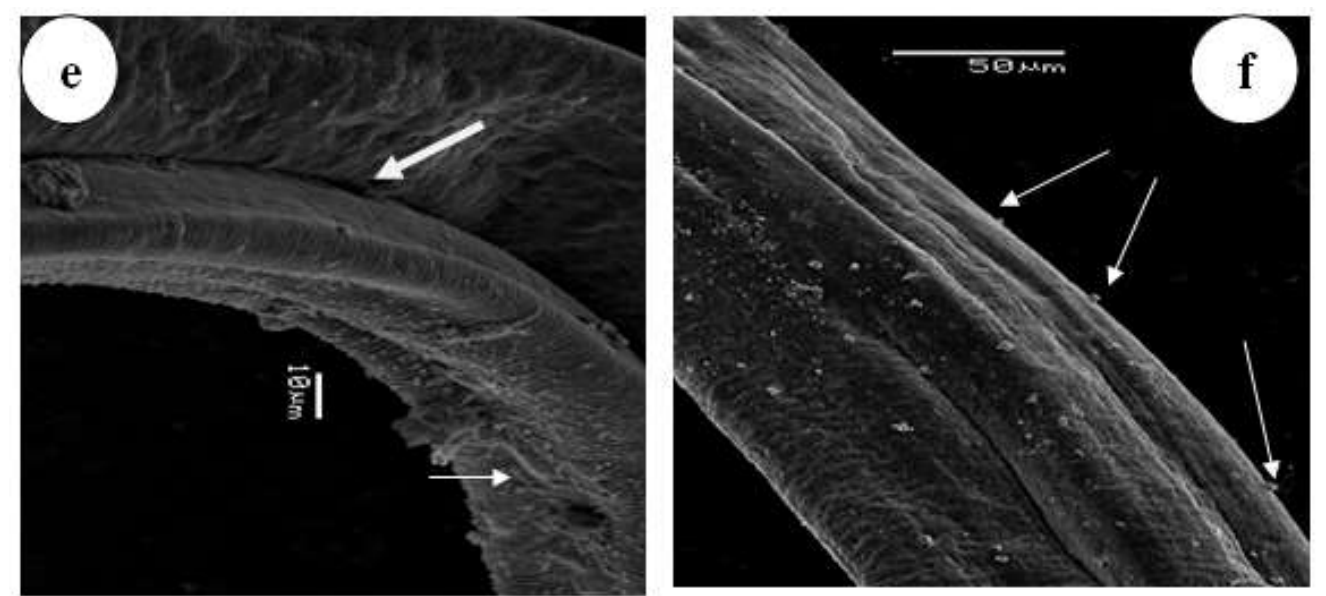

Plate (7): Spirora meleagaris n. sp. male SEM micrographs showing high magnification of the posterior end with caudal papillae (a), numerous unarrangement sessile Cervical papilla (b), explosive or impaired gland (c), unexploded or booming gland (pedunculated rose shape papilla Cervical papilla) (d) cervical region and cervical papilla, longitudinal folds (e), male cervical region; cuticular surface with pedunculated rose shape papilla, transverse striations(f). 